\title{
Long-term durability of the Hancock II porcine bioprosthesis
}

\author{
Giulio Rizzoli, MD \\ Tomaso Bottio, MD \\ Gaetano Thiene, MD \\ Giuseppe Toscano, MD ${ }^{a}$ \\ Dino Casarotto, MD ${ }^{\mathrm{a}}$
}

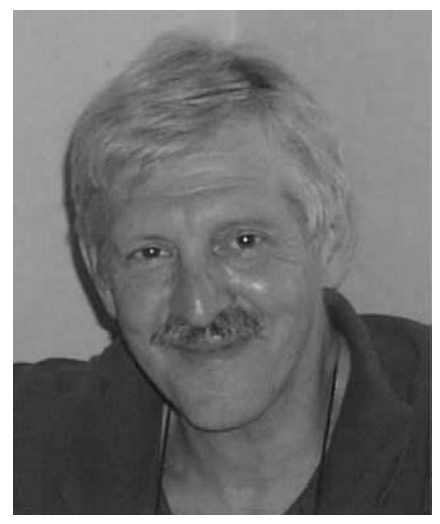

Dr Rizzoli

From the Departments of Cardiovascular Surgery $^{\mathrm{a}}$ and Cardiovascular Pathology, University of Padua Medical School, Padua, Italy.

Supported by grants of "Istituto Superiore di Sanità," and "Ministero Istruzione, Università e Ricerca," Rome, and by "Regione Vimento," Venice, Italy.

Received for publication June 5, 2002; revisions requested Aug 30, 2002; revisions received Oct 16, 2002; accepted for publication Oct 21, 2002.

Address for reprints: Giulio Rizzoli, MD, Institute of Cardiovascular Surgery, University of Padua, Via Giustiniani, 2, Padua 35100, Italy (E-mail: giulio.rizzoli@unipd. it).

J Thorac Cardiovasc Surg 2003;126:66-74

Copyright @ $\odot 2003$ by The American Association for Thoracic Surgery

0022-5223/2003\$30.00+0

doi:10.1016/S0022-5223(02)73618-0
Background: Survival and prosthetic complications of patients receiving the Hancock II second-generation bioprosthesis (Medtronic, Inc, Minneapolis, Minn) in the aortic, mitral, mitral-aortic, and tricuspid positions were analyzed at 15 years' follow-up.

Methods: Between May 1983 and December 1993, 212 patients (104 men and 108 women; mean age, $63 \pm 9$ years; age range, 29-81 years) received 66 aortic, 114 mitral, 26 mitral-aortic, and 6 tricuspid Hancock II valves. Thirty-one percent of patients had previous valve operations, $15 \%$ had concomitant cardiac procedures, and $87 \%$ were in New York Heart Association class III or IV. Follow-up included 1704 patient-years and was $98 \%$ complete, with a median of 9 patient-years (range, 0.013-17.4 years). Forty-six patients were at risk at 14 to 15 years, and 30 were at risk after 15 years.

Results: One hundred twenty-two (57\%) of 212 patients died, 20 of them perioperatively. Fifteen-year actuarial Kaplan-Meier survival was $35.2 \% \pm 3.8 \%$, and freedom from valve-related mortality was $84 \% \pm 3.5 \%$, with no difference on the basis of position or age $(<65$ or $\geq 65$ years). Percentages for freedom from thromboembolism, anticoagulant-related hemorrhage, endocarditis, and paravalvular leak were, respectively, $78.2 \% \pm 4 \%, 83.5 \% \pm 3.6 \%, 95.7 \% \pm 2 \%$, and $97.3 \%$ $\pm 1.4 \%$, with no significant difference between the aortic and mitral positions. Freedom from structural valve deterioration was $71.8 \% \pm 5.6 \%: 88.9 \% \pm 6.2 \%$ in the aortic position versus $59.5 \% \pm 3.9 \%$ in the mitral position $(P=.01)$ and $64.3 \%$ $\pm 3 \%$ in the mitral-aortic position. In patients younger than 65 years, actual freedom from structural valve deterioration was less than that seen in older patients $(84.5 \%$ $\pm 3.5 \%$ vs $95 \% \pm 3.0 \%)$ and was better in the aortic versus the mitral position ( $92 \%$ $\pm 4.5 \%$ vs $82 \% \pm 4.2 \%)$.

Conclusion: The Hancock II porcine valve showed excellent 15-year durability. We recommend its use in patients 65 years of age, as well as in younger patients undergoing aortic replacement.

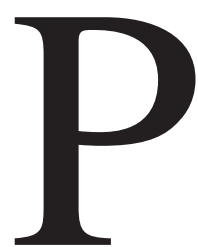

orcine bioprostheses have been used since the late 1960s. ${ }^{1}$ Over time, prosthetic valve-related complications caused by structural ${ }^{2}$ and nonstructural valve dysfunction forced the replacement of many early prosthetic valves within 10 years from implantation. ${ }^{3}$

Tissue processing and valve engineering were modified to enhance long-term performance. In 1982, the second-generation Hancock valve bioprosthesis (Hancock II; Medtronic, Inc, Minneapolis, Minn) was commercialized. It is a porcine bioprosthesis fixed in glutaraldehyde $(0.625 \%)$ at low pressure to preserve the natural collagen crimping, treated with calcium-retarding agent (T6 sodium dodecyl sulfate), and mounted on a low-profile Delrin stent 
TABLE 1. Preoperative and operative data

\begin{tabular}{|c|c|c|c|c|c|}
\hline Sex & $\begin{array}{l}\text { All } \\
\qquad(104 \mathrm{M}, \\
108 \mathrm{~F})\end{array}$ & $\begin{array}{l}\text { Aortic: } \\
27 \% \mathrm{~F} \\
73 \% \mathrm{M}\end{array}$ & $\begin{array}{l}\text { Mitral: } \\
62 \% \mathrm{~F} \\
38 \% \mathrm{M}\end{array}$ & $\begin{array}{l}\text { Double: } \\
50 \% \mathrm{~F} \\
50 \% \mathrm{M}\end{array}$ & $\begin{array}{c}\text { Tricuspid: } \\
67 \% \mathrm{~F} \\
33 \% \mathrm{M}\end{array}$ \\
\hline Mean age (y) & $\begin{array}{l}\text { All } \\
\qquad(212 \text { patients), } \\
63 \pm 9\end{array}$ & $\begin{array}{l}\text { Aortic } \\
\qquad(66 \text { patients), } \\
67 \pm 8.2\end{array}$ & $\begin{array}{l}\text { Mitral } \\
\qquad(114 \text { patients), } \\
61.2 \pm 8.7\end{array}$ & $\begin{array}{l}\text { Mitral-aortic } \\
\text { (26 patients) } \\
61.4 \pm 5.8\end{array}$ & $\begin{array}{l}\text { Tricuspid } \\
\qquad \text { (6 patients), } \\
54.8 \pm 8.9\end{array}$ \\
\hline $\begin{array}{l}\text { Previous valve } \\
\text { procedures (n) }\end{array}$ & $\begin{array}{l}\text { All, } \\
\qquad 66 \text { patients }\end{array}$ & $\begin{array}{l}\text { Aortic, } \\
8 \text { patients }\end{array}$ & $\begin{array}{l}\text { Mitral, } \\
49 \text { patients }\end{array}$ & $\begin{array}{l}\text { Mitral-aortic, } \\
5 \text { patients }\end{array}$ & $\begin{array}{l}\text { Tricuspid, } \\
4 \text { patients }\end{array}$ \\
\hline NYHA class III-IV (\%) & 87 & 75 & 87 & 90 & 90 \\
\hline \multicolumn{6}{|l|}{ Rhythm (\%): } \\
\hline Sinusal & 35 & 83 & 13 & 20 & 17 \\
\hline Atrial fibrillation & 62 & 11 & 86 & 80 & 67 \\
\hline Pacemaker & 3 & 6 & 1 & 0 & 16 \\
\hline \multicolumn{6}{|l|}{ Concomitant procedures ( $\mathrm{n}$ ) } \\
\hline CABG & 18 & 15 & 2 & 1 & 0 \\
\hline Aortoplasty/replacement & 5 & 4 & 0 & 1 & 0 \\
\hline Annulus enlargement & 5 & 5 & 0 & 0 & 0 \\
\hline
\end{tabular}

$C A B G$, Coronary artery bypass grafting.

(DuPont, Wilmington, Del). ${ }^{4}$ Excellent durability has been proved in intermediate follow-up, and therefore an improved long-term performance was expected when compared with that of the Hancock Standard valve bioprosthesis. $^{5-7}$

This study evaluates the 15-year clinical performance and complication rate of patients who underwent aortic, mitral, double-valve, or tricuspid replacement with Hancock II porcine bioprostheses and updates the excellent intermediate follow-up results by Bortolotti and colleagues in the American Journal of Cardiology in 1994. ${ }^{5}$

\section{Patients and Methods}

Between May 1983 and December 1993, 212 patients (104 men and 108 women; mean age, $63 \pm 9$ years; age range, 29-81 years) underwent 238 heart valve replacements with Hancock II porcine bioprostheses. The median age was 63.5 years, and 121 patients were younger than 65 years ( 26 aortic, 73 mitral, 17 mitral-aortic, and 5 tricuspid replacements).

Preoperative data are detailed in Table 1. Sixty-six procedures involved isolated aortic, 99 isolated mitral, and 26 combined mitral-aortic Hancock II placement. An additional 15 mitral Hancock II and 6 tricuspid bioprostheses, with concomitant different aortic prostheses or repairs, were analyzed as single Hancock II procedures.

Eighty-seven percent (184/212) of patients were in New York Heart Association (NYHA) functional class III or IV.

Aortic prosthesis size was $23 \mathrm{~mm}$ in $38.5 \%$ of patients, $25 \mathrm{~mm}$ in $48.5 \%$ of patients, and $27 \mathrm{~mm}$ in $13 \%$ of patients. The indexed effective orifice area was greater than 1 in all but 9 cases. Mitral prosthesis size was $27 \mathrm{~mm}$ in $3.7 \%$ of patients, $29 \mathrm{~mm}$ in $44.8 \%$ of patients, $31 \mathrm{~mm}$ in $42.7 \%$ of patients, and $33 \mathrm{~mm}$ in $8.8 \%$ of patients. The indexed effective orifice area was greater than 1.7 in all but 6 cases.

Sixty-six $(31 \%)$ patients had previously received a different prosthesis: $8(12.2 \%)$ underwent aortic valve replacement, 49
(74.2\%) underwent mitral replacement, 5 (7.6\%) underwent double-valve replacement, and $4(6 \%)$ underwent tricuspid valve replacement.

Concomitant procedures included coronary revascularization (18/212 [8.5\%]) and aortic annular enlargement or aortoplasty (10/212 [5\%]). Explanted bioprostheses underwent microradiographic, histologic, and ultrastructural examination, as previously reported. ${ }^{2}$ Details of pathology will be reported elsewhere.

\section{Surgical Technique}

Median sternotomy, cardiopulmonary bypass, moderate hypothermia, and aortic crossclamping were used in all patients. Cardioplegic arrest was achieved with antegrade cold crystalloid infusion repeated at 20-minute intervals, with additional topical cooling.

Valves were implanted through a transaortic approach or through a paraseptal left atrial incision by using multiple interrupted sutures of 2-0 Ti-Cron (American Cyanamid Co, Danbury, Conn) reinforced by Teflon pledgets. Posterior mitral chordae were occasionally preserved.

Patients with sinus rhythm received oral anticoagulant therapy for 3 postoperative months to maintain a prothrombin time of less than $30 \%$ of the normal value. Patients with chronic atrial fibrillation, left atrial and left ventricular dilatation, double-valve replacement, or previous thrombotic episodes were anticoagulated indefinitely. Aspirin was not prescribed.

\section{Patient Follow-up}

Information was obtained annually by means of direct visits, questionnaires, or telephone interviews. Prospective follow-up was closed at a common date in July 2001. Cumulative follow-up time was 1704 patient-years and was $98 \%$ complete. Median follow-up time was 9 years (range, 0.013-17.4 years), and mean follow-up time was 8.8 years. We limited our analysis to 15 years, with 46 patients at risk between 14 and 15 years and 30 patients at risk thereafter. 
TABLE 2. Postoperative and late data

\begin{tabular}{|c|c|c|}
\hline & Early & Late \\
\hline Deaths & $20(9.4 \%)$ & $102(53.1 \%)$ \\
\hline Cardiac-related death & $15(75 \%)$ & $45(44.5 \%)$ \\
\hline Valve-related death: & $5(25 \%)$ & $17(16.8 \%)$ \\
\hline SVD & & 3 \\
\hline Cerebral hemorrhage & & 3 \\
\hline Periferic hemorrhage & 1 & 1 \\
\hline Thrombosis & 1 & 1 \\
\hline Thromboembolism & 2 & 4 \\
\hline Prosthetic-annulus dehiscence & & 1 \\
\hline Endocarditis & & 3 \\
\hline Sudden & 1 & 1 \\
\hline Anticoagulation & \multicolumn{2}{|c|}{$85.28 \%$} \\
\hline NYHA class I-II & \multicolumn{2}{|c|}{$74.42 \%$} \\
\hline Rhythm & SR $27 \%$ & PM 10\% \\
\hline
\end{tabular}

\section{Statistical Analysis}

Postoperative complications and prostheses-related events (structural valve deterioration [SVD], thromboembolism, anticoagulantrelated hemorrhage, endocarditis, paravalvular leak, reoperations, and valve-related morbidity) were defined as previously published. ${ }^{8}$

Estimates of postoperative complications and prostheses-related events were calculated by means of the Kaplan-Meier method and expressed as percentage \pm SE or percentage $\pm 95 \%$ confidence interval (CI). Statistical comparison of survival curves was made with the log-rank test. Actual versus actuarial freedom from SVD was calculated by using the method of Grunkemeier and coworkers, ${ }^{9}$ and the SE of the actual estimates was calculated with the method of Gaynor and associates. ${ }^{10}$ Actual calculations were made on a prosthetic basis (5 aortic and 20 mitral SVD events).

\section{Results}

Postoperative and follow-up data are summarized in Table 2.

\section{Perioperative (30-Day) Mortality}

Twenty patients died, 9 of them at reoperation. Overall mortality was $9.4 \%$ (95\% CI, 5.8\%-14.2\%): $4.5 \%$ (3/66; $95 \% \mathrm{CI}, 9.4 \%-12.7 \%)$ in the aortic, $11.4 \%(13 / 114 ; 95 \% \mathrm{CI}$, $6.2 \%-18.7 \%$ ) in the mitral, and $15.3 \%$ (4/26; $95 \%$ CI, $4.3 \%$ $35 \%)$ in the mitral-aortic position. All patients were in NYHA class III or IV. Mean patient age was $76 \pm 4.5$ years in the aortic, $66 \pm 8$ years in the mitral, and $63 \pm 3.7$ years in the mitral-aortic position. One patient undergoing aortic replacement had a concomitant Manouguian procedure, ${ }^{11}$ and 1 patient undergoing mitral replacement had an aortacoronary bypass graft. Fifteen deaths were cardiac related, and 5 were valve related.

\section{Late Mortality}

We observed 102 late deaths (102/192 [53.1\%] patients), with an overall 15-year Kaplan-Meier survival of $35.2 \% \pm$
$3.8 \%$ (95\% CI, 27.7\%-42.7\%; Figure 1). Thirty-five deaths occurred in patients undergoing aortic valve replacement (28\% $\pm 8 \%$ 15-year Kaplan-Meier survival), 53 in patients undergoing mitral valve replacement (37\% $\pm 5.3 \%$ 15-year Kaplan-Meier survival), 12 in patients undergoing mitralaortic valve replacement $(31 \% \pm 10 \%$ 15-year KaplanMeier survival), and 2 in patients undergoing tricuspid valve replacement $(62 \% \pm 21 \%$ 15-year Kaplan-Meier survival).

These survivals were not significantly different. Fifteenyear Kaplan-Meier survival of patients younger than 65 years was $44.5 \% \pm 5 \%$ versus $19 \% \pm 6 \%$ for older patients $(P=.0034)$.

Forty-five (44\%) late deaths were cardiac related, 17 (16.8\%) were valve related, and 40 (39.2\%) were noncardiac and nonvalve related.

\section{Valve-Related Death}

Among the 5 perioperative (early) deaths and 17 late valverelated deaths, 6 (17\%; 1 early and 5 late deaths) occurred in patients undergoing aortic valve replacement (1 prosthetic-valve thrombosis, 1 sudden death, 1 SVD, 1 endocarditis, 1 cerebral event, and 1 peripheral hemorrhagic event), 14 (27\%; 3 early and 11 late deaths) occurred in patients undergoing mitral valve replacement (1 sudden death, 2 SVD, 2 valve endocarditis, 1 prosthetic-annulus dehiscence, 1 prosthetic valve thrombosis, 2 cerebral events, 1 peripheral hemorrhagic event, and 4 thromboembolisms), and the last 2 deaths (17\%; 1 early and 1 late death) occurred in patients undergoing mitral-aortic replacement (both thromboembolisms).

Fifteen-year Kaplan-Meier freedom from valve-related mortality was $84 \% \pm 3.5 \%$ (95\% CI, 75.5\%-89.6\%; Figure 2 ); it was $83 \% \pm 8 \%$ for the aortic position, $79 \% \pm 5.2 \%$ for the mitral position, and $90 \% \pm 6.5 \%$ for the mitralaortic position $(P=.72)$.

Ten valve-related deaths occurred in patients younger than 65 years of age, and 12 occurred in older patients: 15 -year freedom from valve-related death was $87 \% \pm 3.5 \%$ in younger and $73 \% \pm 10 \%$ in older patients $(P=.48)$.

\section{Thromboembolism}

Thirty-two bioprosthesis-related major thromboembolic events occurred in 29 patients (9 in patients undergoing aortic, 16 in patients undergoing mitral, and 7 in patients undergoing mitral-aortic replacement) with 2 early and 4 late deaths ( 4 in patients undergoing mitral and 2 in patients undergoing mitral-aortic valve replacement). Linearized rates were $1.8 \%$ per patient-year in aortic, $1.7 \%$ in mitral, and $2.7 \%$ in double prostheses.

Three prosthetic valve thromboses were observed. One patient undergoing mitral valve replacement underwent successful reoperation of bioprosthetic and left atrium toilette 2 


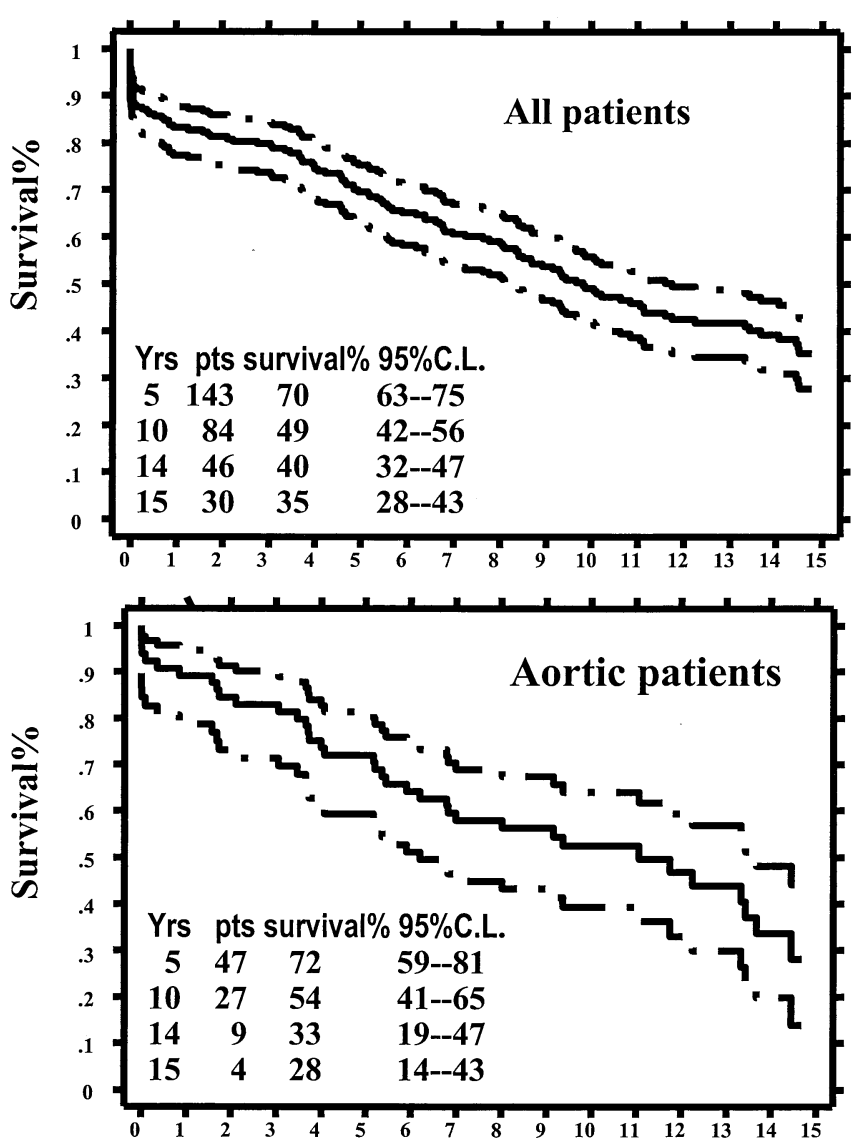

Follow-up (years)

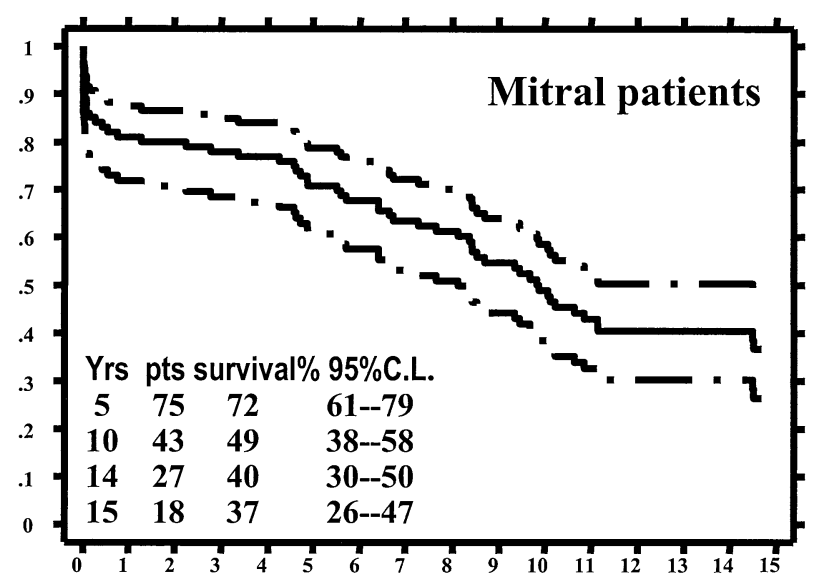

Figure 1. Fifteen-year Kaplan-Meier survival. C.L., Confidence limit.

years after the prosthesis was implanted. The second patient undergoing mitral valve replacement experienced thrombosis 7 years after the operation, was medically treated, and died. The last patient had an aortic thrombosis 5 days after the operation and died. Kaplan-Meier freedom from first thromboembolic occurrence was $78.2 \% \pm 4 \%$ at 15 years, without a statistical difference between the aortic position versus the mitral position or versus the mitral-aortic position $(P=.59)$.

\section{Hemorrhagic Events}

Anticoagulation-related major hemorrhages occurred in 23 patients (6 patients undergoing aortic, 10 patients undergoing mitral, and 7 patients undergoing mitral-aortic replacement). Linearized rates were $1.1 \%$ per patient-year in aortic, $1.1 \%$ in mitral, and $3.7 \%$ in double prostheses.

Fatal hemorrhages were cerebral in 3 patients ( 1 undergoing aortic and 2 undergoing mitral valve replacement) and peripheral in 2 patients (1 undergoing aortic and 1 undergoing mitral valve replacement). Kaplan-Meier freedom from first occurrence of anticoagulant-related hemorrhage was $83.5 \% \pm 3.6 \%$ at 15 years, with significantly lower freedom $(67.3 \% \pm 12 \%)$ in double-valve replacement $(P=.01)$.

\section{Endocarditis}

Five patients had endocarditis (1 undergoing aortic and 4 undergoing mitral valve replacement), and 3 of them (1 undergoing aortic and 2 undergoing mitral valve replacement) died at follow-up. Linearized rates were $0.20 \%$ per patient-year in aortic and $0.44 \%$ in mitral prostheses.

Among the patients undergoing mitral valve replacement, 2 underwent prosthetic valve replacement. KaplanMeier freedom from prosthetic valve endocarditis was $95.7 \% \pm 2 \%$ at 15 years, without a significant difference among positions.

\section{Paravalvular Leak}

Paravalvular leak occurred in 4 patients. We reoperated on 1 patient who had mitral leak 8.6 years after implantation and 2 patients with a double-valve leak 4 and 16 months, respectively, after implantation, both involving only the mitral valve (1 replaced and 1 sutured). The last patient, who had an aortic leak after 4 months, was considered, on 


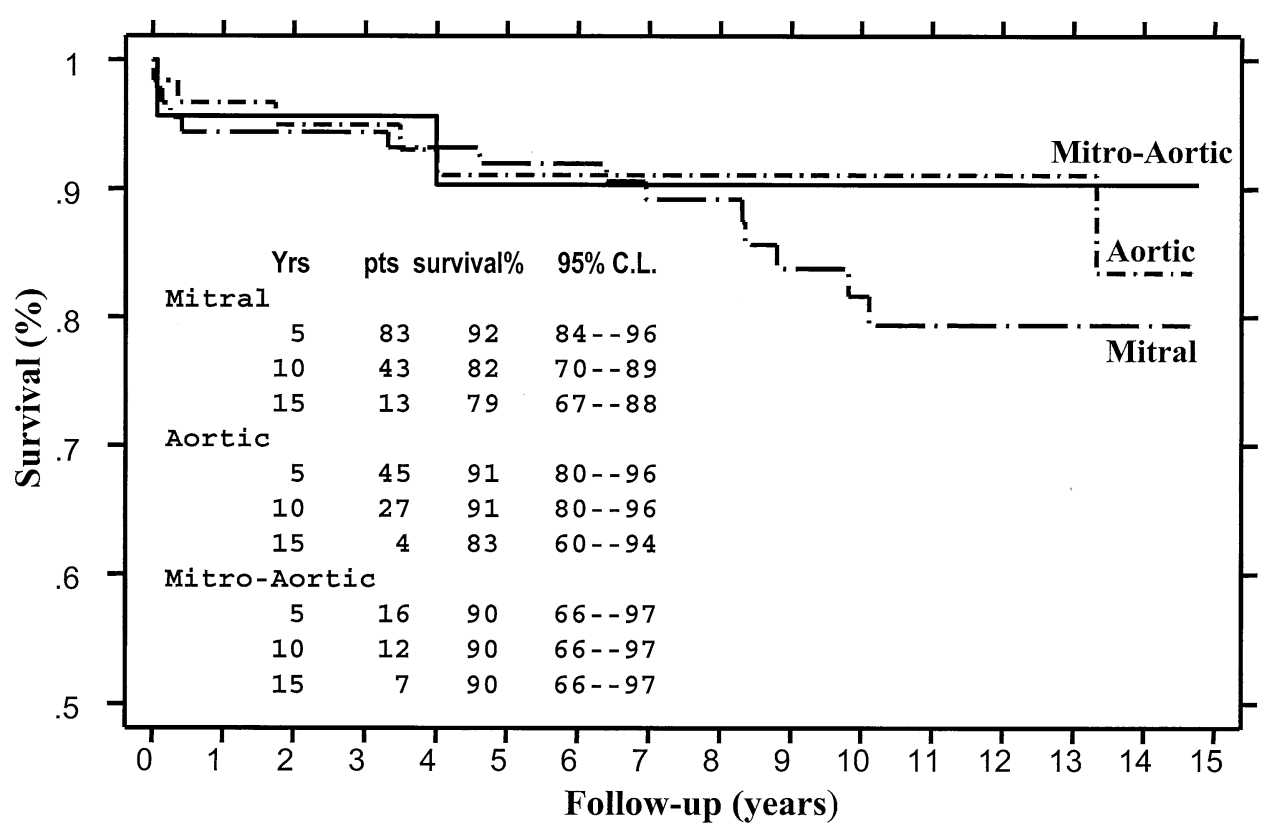

Figure 2. Kaplan-Meier 15-year freedom from valve-related mortality. C.L., Confidence limit.

the basis of 2-dimensional echocardiography, to have a hemodynamically insignificant leak and was medically treated. Linearized rates were $0.19 \%$ per patient-year in aortic, $0.11 \%$ in mitral, and $1.1 \%$ in double prostheses.

Kaplan-Meier freedom from paravalvular leak was $97.3 \% \pm 1.4 \%$ at 15 years, with a significantly lower freedom $(90.4 \% \pm 6.4 \%)$ among the double-valve recipients $(P=.01)$.

\section{Structural Valve Deterioration}

SVD occurred in 22 patients (mean age, $56 \pm 9$ years): 2 receiving aortic, 16 patients receiving mitral, and 4 patients receiving mitral-aortic valve replacements. Among the latter, both valves were affected in 3 patients, and the lone mitral valve was affected in 1 patient. Seventeen patients (12 undergoing mitral, 1 undergoing aortic, and 4 undergoing double-valve replacement) with a mean age of $54 \pm 9$ years underwent reoperation either because of stenosis, incompetence, or both (20 bioprostheses were explanted).

Overall freedom. Fifteen-year actuarial (Kaplan-Meier) freedom from SVD was $71.8 \% \pm 5.6 \%$ (95\% CI, 58.9\%81.2\%; Figure 3). Actual SVD freedom was $88 \% \pm 2.5 \%$.

Freedom by position. Fifteen-year actuarial (KaplanMeier) freedom from SVD was $88.9 \% \pm 6.2 \%(95 \% \mathrm{CI}$, $62.4 \%-97.1 \%)$ in the aortic position, $59.5 \% \pm 3.9 \%(95 \%$ CI, 39.8\%-74.6\%) in the mitral position, and $64.3 \% \pm 3.0 \%$ (95\% CI, 29.8\%-85.1\%) in double valves (Figure 4). The difference between the aortic and mitral position was significant $(P=.01)$. Given 5 aortic and 20 mitral SVD events, the actual estimate was $92.4 \% \pm 3.3 \%$ in the aortic position and $85.3 \% \pm 3.2 \%$ in the mitral position.

Freedom by age. Fifteen-year actuarial (Kaplan-Meier) freedom from SVD was $69 \% \pm 7 \%$ in patients younger than 65 years of age and $83 \% \pm 8 \%$ in older patients.

Fifteen-year actual SVD freedom was $84.5 \% \pm 3.5 \%$ in patients younger than 65 years and $95 \% \pm 3.0 \%$ in older patients (Figure 5).

Freedom by age and position. Fifteen-year actual SVD freedom in patients younger than 65 years was $82 \% \pm 4.2 \%$ in the mitral position and $92 \% \pm 4.5 \%$ in the aortic position $(P=.0002)$. In older patients freedom was $91.8 \% \pm 4.6 \%$ and $93.2 \% \pm 4.8$, respectively. Concerning the isolated aortic position, both SVD events occurred in patients younger than 65 years (50 and 56 years, respectively).

Interval to replacement. The interval from implantation to replacement was $9.7 \pm 3.8$ years (1.7-16 years). It was $8.5 \pm 2.8$ years in the aortic position and $9.5 \pm 3.7$ years in the mitral position.

\section{Reoperations}

Thirty-one patients underwent reoperation: 3 patients undergoing double-valve replacement underwent reoperation on a failing pericardial tissue valve ( 2 patients) and a failing Liotta bioprosthesis (1 patient). One thrombosed Hancock II mitral prosthesis was preserved after thrombus removal. Twenty-seven patients had replacement of 29 Hancock II bioprostheses at a mean operative age of $56.9 \pm 9.8$ years $(1$ in the aortic, 20 in the mitral, and 6 in the mitral-aortic 


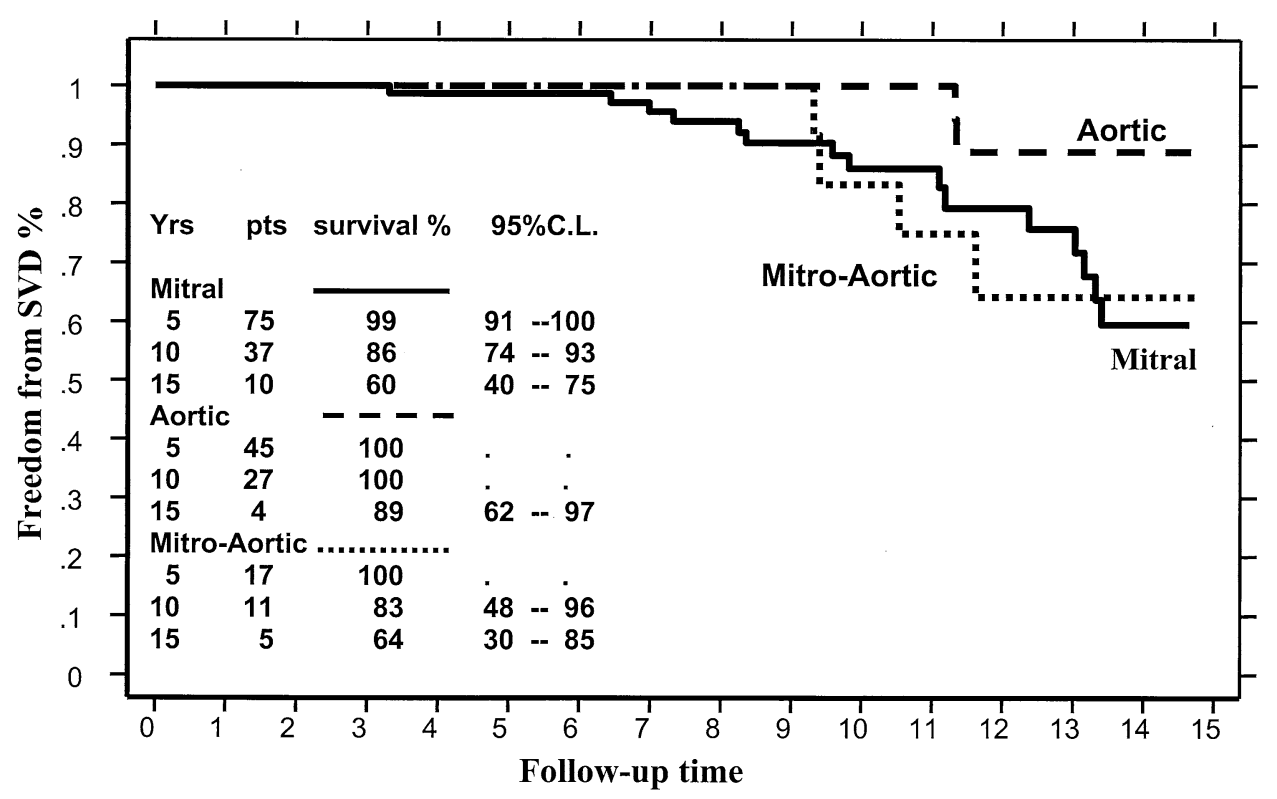

Figure 3. Kaplan-Meier 15-year freedom from SVD by position. The 95\% confidence band (C.L.) is shown.

positions). The linearized rate was $2.1 \%$ per patient-year in the mitral position, $0.4 \%$ in the aortic position, and $3.0 \%$ in the mitral-aortic position. The overall reoperation freedom (Figure 5) was $69.8 \% \pm 5.4 \%$ at 15 years $(95 \%$ CI, $57.7 \%$ $79 \%$ ). Causes of reoperation are reported in Table 3. In 2 patients reoperated on elsewhere, the cause of reoperation was unknown.

Significantly lower freedom from reoperation was observed in the mitral position $(53.4 \% \pm 9 \%)$ versus in the aortic position $(94.4 \% \pm 5.4 \%, P=.0038)$. The actual freedom of Hancock II reoperation was $81 \% \pm 3.7 \%$ at 15 years in patients younger than 65 years of age and $89.6 \pm$ $3.8 \%$ in older patients.

\section{Valve-Related Complications}

There were 86 valve-related complications, including hemorrhage, embolism, endocarditis, paravalvular leak, thrombosis, and SVD. There were 71 first occurrences and 15 recurrent episodes.

Freedom from all valve-related complications was $40.5 \%$ $\pm 4.5 \%$ at 15 years. According to prosthetic positions and operative age, freedom from all valve-related complications was not significantly different. At the end of follow-up, $74.42 \%$ of the patients were in NYHA functional class I or II. Twenty-seven percent of patients were in sinus rhythm, $63 \%$ were in atrial fibrillation, and $10 \%$ had a pacemaker. Most patients (85.28\%) were orally anticoagulated (warfarin), including $87.28 \%$ who were in sinus rhythm.

\section{Discussion}

In the time interval of this study, 1799 mechanical prostheses and 561 biologic prostheses of different makes were implanted. The indications for the use of bioprostheses were identical to those recently reported by the American Heart Association, ${ }^{12}$ with the adjunct of patients from underdeveloped countries or from particularly underdeveloped areas within the country. This study summarizes our 15-year experience with the use of the Hancock II porcine bioprosthesis.

Clinical durability of first-generation porcine bioprostheses was limited by calcification and primary cusp tears. ${ }^{2,13-16}$ Improvements were obtained by eliminating the right muscle shelf, preserving the natural collagen crimping with glutaraldehyde fixation at low pressure, designing a new stent (Delrin), and adding an anticalcification treatment with sodium dodecyl sulfate (T6) to enhance both hemodynamic performance and long-term durability. In our institute the clinical use of the Hancock II model started in 1983, and in 1994, Bortolotti and colleagues ${ }^{5}$ reported excellent intermediate-term results with no evidence of calcification at a mean follow-up of $4.5 \pm 2.6$ years. In 1995, Bortolotti and colleagues ${ }^{17}$ documented an improved long-term survival and durability up to 8 years with the Hancock II bioprosthesis compared with that of the Hancock Standard bioprosthesis. This conclusion was recently supported by Ikonomidis and coworkers ${ }^{18}$ and is also confirmed from the 15-year freedom from SVD we are reporting in this article, which was higher both in the aortic and the mitral position than that previously reported for patients receiving the Hancock Standard bioprosthesis $(P=.001) .{ }^{17}$ Nevertheless, these observations are seriously confounded by differences in operative age, which was $48 \pm 12$ years in the Hancock Standard series reported by Bortolotti and colleagues ${ }^{17}$ 


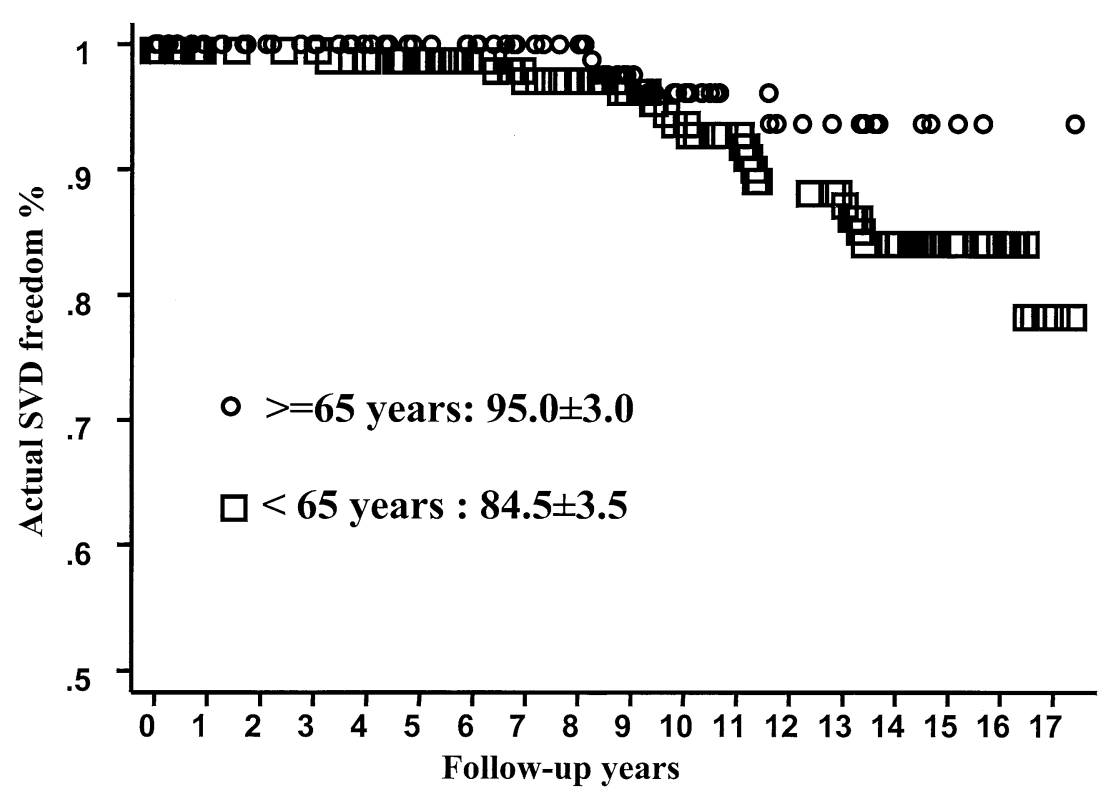

Figure 4. Actual 15-year freedom from SVD according to operative age.

compared with $63 \pm 9$ years in the present Hancock II series.

\section{Clinical Results}

Compared with the series by David and associates ${ }^{19}$ and Legarra and coworkers ${ }^{20}$, the overall 15-year Kaplan-Meier survival of our experience was lower. The article by Legarra and coworkers on long-term results with the Hancock II valve appears unreliable because they claim to have started implantation in 1978 despite the fact that clinical use of the Hancock II bioprosthesis dates only to 1983. The excellent results of the article by David and associates ${ }^{19}$ are probably difficult to reproduce. However, our survival with the Hancock II valve is within the international standard and similar to recent results ${ }^{21}$ obtained in Sweden with the Biocor porcine valve (St Jude Medical, Inc, St Paul, Minn), a new-generation prosthesis with zero pressure fixation, composite leaflets, and a low-profile flexible acetal copolymer (Celcon) stent, which started to be used in 1983 .

The perioperative mortality of our single-valve series compared with that in the series by David and associates, ${ }^{19}$ which does not include double-valve replacements, was higher: $8.8 \%(16 / 180)$ versus $5.8 \%(57 / 980, P=.12)$. The difference was probably related to NYHA class II and IV prevalence ( $87 \%$ vs $79 \%$ ) and to the higher reoperation prevalence of our series (34\% of patients vs $25 \%$ of patients in the series by David and associates). In fact, almost half of our perioperative deaths occurred in patients who had undergone previous valve operations. Our patients undergoing aortic operations were older $(P=.07)$ and our patients undergoing mitral valve replacement were younger $(P=$ .001) than those in the study by David and associates. ${ }^{19}$ These differences confounded late survival and late complication comparisons between the 2 series. Small differences in operative ages were responsible for large differences in survival at 15 years, when natural death obscured disease-specific mortality. Compared with the results of the series by David and associates, we reported a higher incidence of thromboembolic events. Our protocol did not include the use of aspirin therapy, anticoagulation control was in the physicians' hands, and anticoagulation clinic support was rare. Hemorrhagic events were related to anticoagulation use in $87 \%$ of patients in sinus rhythm, losing one of the theoretical advantages of bioprosthetic devices. Moreover, despite high reoperation rates, young patients had very satisfactory long-term survival, confirming that bioprosthetic reoperations did not seriously affect survival, as previously reported. ${ }^{19}$

Noteworthy is our finding of 3 thrombosed valves, which was previously reported in a Hancock Standard series. ${ }^{22}$ Unfortunately, just a single patient underwent reoperation. The operative notes recorded an atrial thrombosis with extension to the valve, which was surgically cleaned and preserved without further complications. The pathogenesis remained unclear in the other 2 patients.

Endocarditis was rare and mostly in the mitral position, as documented in previous reports. ${ }^{19-21}$ When occurring, it was aggressive and lethal.

Paravalvular leak was also rare and more frequent in patients undergoing double-valve replacement. 


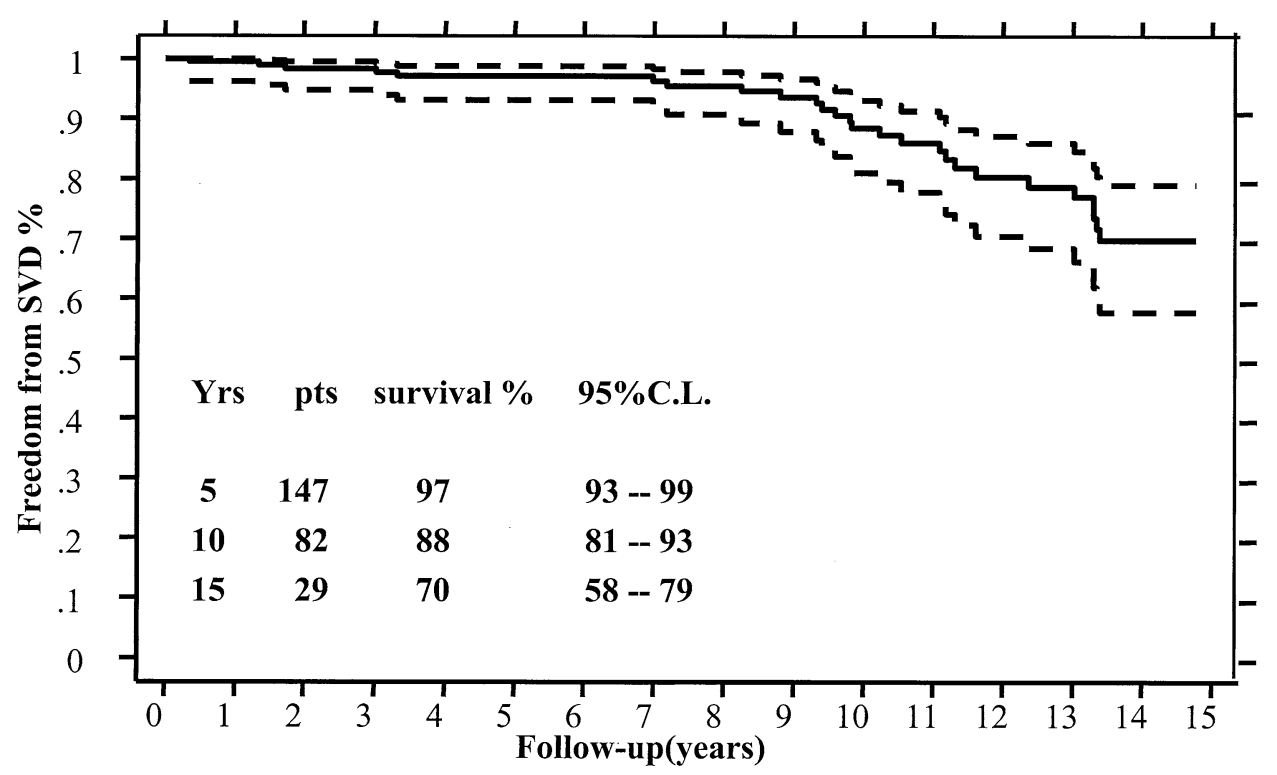

Figure 5. Kaplan-Meier 15-year freedom from reoperation. The 95\% confidence band (C.L.,) is shown.

\section{Structural Valve Deterioration}

We observed 22 cases of SVD (72\% 15 -year actuarial freedom and $88 \%$ actual freedom). Seventeen patients underwent reoperation, and 3 died.

Actuarial Kaplan-Meier and actual freedom from SVD were significantly lower in the mitral than in the aortic position, as previously reported. ${ }^{19}$ In the aortic position, overall 15-year actual results, as well as age-stratified results, were identical to the results observed by Banbury and associates ${ }^{23}$ with the use of the Carpentier-Edwards bovine pericardial valve (Edwards Lifesciences, Irvine, Calif). In the mitral position the overall 10-year actuarial freedom of SVD was $86 \% \pm 4.7 \%$, which was similar to the results of the Carpentier-Edwards pericardial valve research reported by Jamieson and coworkers ${ }^{24}$ and superior to the results observed with the Carpentier-Edwards supra-annular porcine valve, despite the younger overall age of patients undergoing mitral valve replacement in our series $(61 \pm 9$ vs $64 \pm 12$ years).

Younger patients were significantly more affected by SVD than older patients. By means of age stratification, only the mitral position was a significant incremental risk factor limited to the younger age group, possibly because of the small number of our younger patients undergoing aortic valve replacement (26/66). Therefore we consider younger age and mitral position predictive of SVD, as previously stated by David and associates. ${ }^{19}$ In patients undergoing isolated aortic procedures, $100 \%$ 15-year actual freedom from SVD was observed if age at the time of the operation was 65 years or greater. This result, which is identical to that reported in the article by Jamieson and colleagues, ${ }^{25}$ adds to confidence in the use of aortic Hancock II prostheses
TABLE 3. Causes of reoperation

\begin{tabular}{lcrc}
\hline Failure & Aortic & Mitral & Mitral-aortic \\
\hline Endocarditis & & 2 & \\
SVD & 1 & 12 & 4 \\
Paravalvular leak* & & 1 & 2 \\
Prophylactic replacement† & & 2 & \\
Left atrium and prosthetic toilette & & 1 & \\
Unknown§ & & 2 & \\
Total & 1 & 20 & 6 \\
\hline
\end{tabular}

*Dehiscence: prosthesis annulus detachment.

tReoperation because of other valve-related complications.

$\ddagger$ Prosthetic-sparing procedure.

$\S$ Patients reoperated elsewhere.

by adding 4 more patients, who were followed by us for 15 years, to the 5 reported in their article.

The higher failure propensity of the Hancock II mitral valve might be ascribed to hemodynamic factors ( $\Delta$ pressure and shear stress) unique to this position. ${ }^{19}$ Increased commissural stress caused by low-profile design has been indicated as a possible cause of the high failure rate of the supra-annular Carpentier-Edwards porcine valve. ${ }^{24}$ However, a lower reoperation rate caused by mitral SVD compared with aortic SVD has been reported at 15-year follow-up by Myken and colleagues ${ }^{21}$ with the use of the Biocor porcine prosthesis and by Bottio and coworkers ${ }^{26}$ at 9 years' follow-up.

Unlike Butany and associates, ${ }^{27}$ we did not observe SVD cases with pannus overgrowth. Butany and associates pointed out that the high prevalence of pannus $(60 \%$ of explanted mitral valves) might be due to the preservation of 
the mitral subvalvular apparatus, a policy that we seldom used during the time span of the study. Fibrous pannus formation on the porcine cusps of the ventricular side has been observed in tricuspid replacement ${ }^{28,29}$ and related to excessive prosthetic dimension. ${ }^{30}$ We implanted mitral bioprostheses larger on average than those reported by David and associates, ${ }^{19}$ thus excluding this possible mechanism.

In conclusion, our perioperative mortality was probably related to previous valve operations. The incidence of all valve-related complications was low in both the aortic and the mitral position. Hancock II bioprostheses had excellent 15-year durability when compared with previous results with Hancock Standard bioprostheses, possibly because of anticalcification treatment mitigating mineralization, although this remains to be proved. This is an important finding because of the exponential increase of patients with degenerative aortic valve stenosis in aging populations. Although the oldest patients will experience the largest advantage, it is noteworthy that younger aortic patients might enjoy anticoagulation freedom at low SVD risk with this prosthesis.

\section{References}

1. Carpentier A, Dubost C, Lane E, et al. Continuing improvements in valvular bioprostheses. J Thorac Cardiovasc Surg. 1982;83:27-42.

2. Milano A, Bortolotti U, Talenti E, et al. Calcific degeneration as the main cause of porcine bioprosthetic valve failure. Am J Cardiol. 1984;53:1066-70.

3. Bortolotti U, Milano A, Thiene G, Mazzucco A. Original expectations of the Hancock valve and 20 years of clinical reality. Eur J Cardiothorac Surg. 1992;6(Suppl 1):S75-8.

4. Wright JTM, Eberhardt CE, Gibbs ML, Saul T, Gilpin CB. Hancock II-an improved bioprosthesis. In: Chon LH, Galluci V, editors. Cardiac bioprostheses. New York: Yorke Medical Books; 1982. p. 425-44.

5. Bortolotti U, Milano A, Mazzaro E, Thiene G, Talenti E, Casarotto D. Hancock II porcine bioprosthesis: excellent durability at intermediateterm follow-up. J Am Coll Cardiol. 1994;24:676-82.

6. David TE, Armstrong S, Sun Z. Clinical and hemodynamic assessment of the Hancock II bioprosthesis. Ann Thorac Surg. 1992;54:661-8.

7. David TE, Armstrong S, Sun Z. The Hancock II bioprosthesis at 12 years. Ann Thorac Surg. 1998;66:S95-8.

8. Edmunds LHJ, Clark RE, Cohn LH, Miller DC, Weisel RD. Guidelines for reporting morbidity and mortality after cardiac valvular operations. J Thorac Cardiovasc Surg. 1988;96:351-3.

9. Grunkemeier GL, Anderson RP, Miller DC, Starr A. Time related analysis of nonfatal heart valves complication: cumulative incidence (actual) vs. Kaplan-Meier (actuarial). Circulation. 1997;96(Suppl 9): II70-5.

10. Gaynor JJ, Feuer EJ, Tan CC, et al. On the use of cause-specific failure and conditional failure probabilities: examples for clinical oncology. $J$ Am Stat Assoc. 1993;88:400-9.

11. Manouguian S, Seybold-Epting W. Patch enlargement of the aortic valve ring by extending the aortic incision into the anterior mitral leaflet. New operative technique. J Thorac Cardiovasc Surg. 1979;78: 402-12.
12. Bonow RO, Carabello B, de Leon AC, et al. ACC/AHA guidelines for the management of patients with valvular heart disease. Executive summary. A report of the American College of Cardiology/American Heart Association Task Force on Practice Guidelines (Committee on Management of Patients With Valvular Heart Disease). J Heart Valve Dis. 1998;7:672-707.

13. Schoen FJ, Levy R, Piehler HR. Pathological considerations in replacement cardiac valves. Cardiovasc Pathol. 1992;1:29-52.

14. Burdon TA, Miller DC, Oyer PE, et al. Durability of porcine valves at fifteen years in a representative North American population. $J$ Thorac Cardiovasc Surg. 1992;103:238-52.

15. Jamieson WRE, Munro AI, Miyagishima RT, Allen P, Burr LH, Tyers GFO. Carpentier-Edwards standard porcine bioprostheses: clinical performances to seventeen years. Ann Thorac Surg. 1989;48:S81-2.

16. Akins CW, Carroll D, Buckley MJ, Daggett WM, Hilgenberg AD, Austen WG. Late results with Carpentier-Edwards porcine bioprostheses. Circulation. 1990;82(Suppl 4):65-74.

17. Bortolotti U, Milano A, Mossutto E, Mazzaro E, Thiene G, Casarotto D. Porcine valve durability: a comparison between Hancock Standard and Hancock II bioprostheses. Ann Thorac Surg. 1995;60:S216-20.

18. Ikonomidis JS, Ivanov J, Miller DC, Armstrong S, David TE. Improved durability with the new Hancock II bioprosthesis [abstract]. Circulation. 1999;100(Suppl):I525.

19. David TE, Ivanov J, Armstrong S, Feindel CM, Cohen G. Late results of heart valve replacement with the Hancock II bioprosthesis. J Thorac Cardiovasc Surg. 2001;121:268-77.

20. Legarra JJ, Llorens R, Catalan M, et al. Eighteen-year follow up after Hancock II bioprosthesis insertion. J Heart Valve Dis. 1999;8:16-24.

21. Mykèn P, Bech-Hanssen O, Phipps B, Caidahl K. Fifteen years follow-up with the St. Jude Medical Biocor Porcine Bioprosthesis. J Heart Valve Dis. 2000;9:415-22.

22. Bortolotti U, Milano A, Mazzucco A, et al. Results of reoperation for primary tissue failure of porcine bioprostheses. J Thorac Cardiovasc Surg. 1985;90:564-9.

23. Banbury MK, Cosgrove DM, White JA, Blackstone EH, Frater RWM, Okies JE. Age and valve size effect on the long term durability of the Carpentier-Edwards aortic pericardial bioprosthesis. Ann Thorac Surg. 2001;72:753-7.

24. Jamieson WRE, Marchand MA, Pelletier CL, et al. Structural valve deterioration in mitral replacement surgery: comparison of CarpentierEdwards supra-annular porcine and Perimount pericardial bioprostheses. J Thorac Cardiovasc Surg. 1999;118:297-305.

25. Jamieson WRE, David TE, Feindel CMS, Miyagishima RT, Germann E. Performance of the Carpentier-Edwards SAV and Hancock-II porcine bioprostheses in aortic valve replacement. $J$ Heart Valve Dis. 2002;11:424-30

26. Bottio T, Rizzoli G, Gerosa G, Thiene G, Casarotto D. Mid-term follow-up in patients with Biocor porcine bioprosthesis. Cardiovasc Surg. 2002;10:238-44.

27. Butany J, Yu W, Silver MD, David TE. Morphologic findings in explanted Hancock II porcine bioprostheses. J Heart Valve Dis. 1999; 8:4-15.

28. Rizzoli G, De-Perini L, Bottio T, Minutolo G, Thiene G, Casarotto D. Prosthetic replacement of the tricuspid valve: biological or mechanical? Ann Thorac Surg. 1998;66(Suppl 6):S62-7.

29. Guerra F, Bortolotti U, Thiene G, et al. Long-term performance of the Hancock porcine bioprosthesis in the tricuspid position. A review of forty-five patients with fourteen-year follow-up. Thorac Cardiovasc Surg. 1990;99:838-45.

30. Nakano K, Eishi K, Kosakai Y, et al. Ten-year experience with the Carpentier-Edwards pericardial xenograft in the tricuspid position. J Thorac Cardiovasc Surg. 1996;111:605-12. 